American Journal of Applied Sciences 7 (4): 473-479, 2010

ISSN 1546-9239

(C) 2010Science Publications

\title{
Work Posture and Back Pain Evaluation in a Malaysian Food Manufacturing Company
}

\author{
Baba Md. Deros, Dian Darina Indah Daruis, Ahmad Rasdan Ismail and Ahmad Rifqi Abdul Rahim \\ Department of Mechanical and Materials Engineering, Faculty of Engineering and Built Environment, \\ University Kebangsaan Malaysia, Bangi Selangor 43600 Malaysia
}

\begin{abstract}
Problem statement: A cross-sectional study was conducted among workers at a processed food manufacturer in Malaysia. The main objective of the study was to determine the prevalence of back pain among workers who perform manual material handling. In addition, the study also investigated the effectiveness of the interventions provided by the employer to reduce the risk of back pain. Approach: A total of 60 workers had participated in the study. Socio-demographic information and back pain symptoms were obtained using Standardized Nordic Questionnaire (SNQ) for analysis of musculoskeletal Symptoms. WinOWAS software was used to identify the respondent's working posture. Results: Study results showed that lifting posture contributed the highest percentage of upper extremities back pain (45\%) and lower extremities back pain (80\%). There was a significant relationship at level $\mathrm{p} \leq 0.05$ for posture working repeatedly and lifting weight above head level. The interventions provided by the employer showed $82 \%$ of the respondents gave a positive feedback for training provided. As for personal protective equipment and mechanical aid, both showed positive results at 84.61 and $100 \%$ respectively. Chi-square analysis results showed, respondents' age has significant effect on standing posture for $10 \mathrm{~min}(\mathrm{p}<0.01)$ for pain at the upper back. On the other hand for gender factor, correlation with; standing for $10 \mathrm{~min}$, hold on load, reaching load, putting loads above head level, turning load and static standing, has significant effect on upper back pain at $\mathrm{p}<0.05$. Gender also showed significant correlation with; doing repetitive task, reaching load and putting loads above head height, which contributed significantly to lower back pain at $p<0.05$. Conclusion: The study suggested that all manual handling activities should be replaced with mechanical aids to reduce prevalence of back pain.
\end{abstract}

Key words: Posture, OWAS, prevalence, manual material handling

\section{INTRODUCTION}

Back pain problem has been a culprit to many occupational safety and health problems. In 2006, more than 1000 cases of back injuries have been reported in Malaysia and none of the cases were promptly solved . Back pain problems have been one of the main reasons for high absenteeism rate in many countries (Saraji et al., 2004). Lack of ergonomics knowledge and interventions in daily activities of the workers as well as excessive manual material handling are among the many factors contributing to study related disorders (Koda and Ohara, 1999; Yeung et al., 2003). It has been reported in the US, there were 70,580 cases of occupational Musculoskeletal Disorders (MSD) and that includes back pain (Bernard, 1997).

Any job that involves heavy labor or Manual Material Handling (MMH) may be in a high-risk category. MMH entails lifting, but also includes climbing, pushing, pulling and pivoting, all of which pose the risk of injury to the back (Triano and Selby, 2006). The term MSD refers to conditions that involve the nerves, tendons, muscles and supporting structures of the body (Bernard, 1997). Ranging from back strains to carpal tunnel syndrome, it is common for employers to find MSD accounting for $40 \%$ or more of their injury cases and $60 \%$ of their workers compensation costs (Adam, 2005). In other words, MSD are always being associated with $\mathrm{MMH}$.

Most data concerning back pain are related to developed countries and information about back pain in developing and low-income countries are still lacking (Ghaffari et al., 2006). In Malaysia, the awareness of back pain due to study is still at a budding stage. The issue is considered new in Malaysia compared to other developed countries and it is still being promoted by the

Corresponding Author: Baba Md. Deros, Department of Mechanical and Materials Engineering,

Faculty of Engineering and Built Environment, University Kebangsaan Malaysia,

Bangi Selangor 43600 Malaysia 
professionals especially the Occupational Safety and Health (OSH) practitioners to enhance the awareness level to all Malaysians. Besides affecting the workers health, back pain and MSD can also lower productivity. According to Punnet and Wegman (2004), back pain is associated with substantial financial cost and loss of quality of life. For example, a study of Low Back Pain (LBP) among Iranian industrial workers by Ghaffari et al. (2006) found that the 1 year prevalence of self-reported LBP in the Iranian industrial population was $21 \%$. The prevalence rate of absence due to LBP was $5 \%$ per annum.

The aims of the current study are twofold; firstly, it is a pilot study to determine the prevalence of back pain among workers in a food manufacturing industry who perform the MMH and secondly, to determine the effectiveness of the system implemented by the employer in reducing back pain problems of their workers.

\section{MATERIALS AND METHODS}

The study was conducted in a food manufacturing company in Malaysia. Subjects were production operators from various sections in the production plant. There were 200 workers in the production department and the number of male to female workers is in $3: 1$ ratio. The male workers comprised of 85 local men and the rest were either Nepalese or Indonesian.

Data collection depended on self-reported questionnaire which was based on Nordic questionnaire survey, as well as subjects working posture analysis using the OWAS method. The sample was determined randomly from a pool of workers who confirmed by the employer to have these criteria; permanent and experienced workers from the operation section in the production department, actively involved in manual handling and has never involved in any type of accidents and no known disability or injury especially at back muscle and spine. The sample size obtained from the sampling process was 60 . According to Corner and Kirkwood (1991), sample size can be determined by a formula as such:

$\mathrm{N}=\mathrm{P}(1-\mathrm{P}) / \mathrm{e}^{2}$

Where:

$\mathrm{P}=$ Prevalence of low back pain reports

$\mathrm{e}=$ Sampling error usually 0.05 (Pinder, 2000)

However there were no official reports made by the workers of the food manufacturing company studied, hence the formula is irrelevant. The number of sample decided was thought to be an appropriate size since it covers more than a quarter of the workers. Each subject was interviewed about their past experience regarding any injuries, accidents or disabilities if there was any; prior to working in the factory. The subjects were briefed on the purpose of the study and agreement forms were signed prior to the data collection process. Subjects' ages were about 19-54 years old. It was shown in the literature that prevalence of back pain is relatively consistent for workers aged between 2565 years old (Biering-Sorensen et al., 1989; Guo et al., 2004).

The survey: There were three parts in the questionnaire. Part A and part B were about subjects' personal details and working details. Part $\mathrm{C}$ was the main part of the questionnaire, regarding musculoskeletal symptoms analysis and it was adapted from standardized Nordic questionnaire (Kourinka et al., 1987). Prior to the actual study, 10 subjects were randomly chosen to pretest and gave their feedback on the questionnaire. The questionnaire was in Malay language, the national language of the local workers.

Work posture analysis: Ovako Working posture Analysis System (OWAS) is a simple and systematic method to analyze working posture by observing the work being carried out (Karhu et al., 1977). The analysis was carried out with the aid of WinOWAS ${ }^{\mathbb{B}}$ software. The software focuses on three body parts, the back, arms and legs. Observations were carried out for $8 \mathrm{~h}$ per day during weekdays and only specific working postures that can be categorized according to OWAS were video-taped. The type and frequency of the different postures assumed during work are recorded along with an estimate of the load handled by the subject being observed. The basic idea of this observational technique is to collect data through postural observations (usually 100 observations) made at set intervals (usually at every $30 \mathrm{sec}$ ) over a set time period (Matilla et al., 1993). The risk of injuries due to awkward work postures can be classified into the following four categories:

- Category 1: Normal and natural postures with no harmful effect on the musculoskeletal system-i.e., no action required

- Category 2: Postures with some harmful effect on the musculoskeletal system-i.e., corrective actions required in the near future

- Category 3: Postures have a harmful effect on the musculoskeletal system-i.e., corrective actions should be done as soon as possible 
Am. J. Applied Sci., 7 (4): 473-479, 2010

- Category 4: The load caused by these postures has a very harmful effect on the musculoskeletal system-i.e., corrective actions for improvement required immediately. According to Karhu et al. (1977), in category 4, the study posture in dangerous and category 2-4 were identified as awkward postures

\section{RESULTS}

Table 1 showed the personal background of the respondents. A total of 60 respondents were involved in this study and $72 \%$ of the respondents were local while the rest were Nepalese and Indonesians. Table 2 showed the relationship between few demographic factors of the respondents and their back pain problem. In order to study the back pain problems according to their working postures, the data has to be analyzed using Chi squared analysis $\left(\mathrm{x}^{2}\right)$. From the analysis, it was found that gender factor have significant relationships (significant level $\mathrm{p} \leq 0.05$ ) with Upper Back Pain (UBP) for postures pushing loads, holding loads, rotating during lifting, standing statically for $10 \mathrm{~min}$, reaching and lifting loads above head level.

Trend of MSD: Table 3 showed the trend of MSD among the respondents in the plant. It was shown that posture with pushing activity were causing $20 \%$ of the respondents to experience UBP while and $42 \%$ to feel lower back pain. For pulling activity, 25\% respondent experienced UBP and 38\% for the lower back pain. Forty-five percent of the respondents complained about UBP for lifting activity and $80 \%$ complained about lower back pain. This activity showed the highest complaints from the respondents. Based on on-site observation, it is after all the activity that is done by the majority of the workers.

Table 1: Respondents working background

\begin{tabular}{lcl}
\hline Information & Frequency $(\%)$ & Min \pm SD \\
\hline Age & $41(68.3)$ & $35.50 \pm 11.735$ \\
Male & $19(31.7)$ & \\
Female & $14(23.3)$ & - \\
Tinning & $15(25.0)$ & - \\
Labeling & $4(6.7)$ & - \\
Botling & $10(16.7)$ & - \\
Soy sauce & $7(11.7)$ & - \\
Pepper grinding & $1(1.7)$ & - \\
1 kg packet & $8(13.3)$ & - \\
Mixing & $1(1.7)$ & - \\
Sacheting & & $11.20 \pm 11.393$ \\
Working experience (years) & \\
working shifts & $51(85.0)$ & \\
Morning & $9(15.0)$ & \\
Evening & & \\
Min of medical leaves & $58(96.7)$ & \\
$\leq 2$ times per month & $1(1.7)$ & \\
$3-4$ times per month & $1(1.7)$ & \\
$\geq 5$ times per month & & \\
Min of no-pay leaves & $58(96.7)$ & \\
$\leq 2$ times per month & $1(1.7)$ & \\
$3-4$ times per month & $1(1.7)$ & \\
$\geq 5$ times per month &
\end{tabular}

Table 2: Relationship between working postures, age, gender and smoking habit

\begin{tabular}{|c|c|c|c|c|c|c|c|}
\hline \multirow[b]{2}{*}{ Factors } & & \multicolumn{2}{|l|}{ Age } & \multicolumn{2}{|c|}{ Gender } & \multicolumn{2}{|c|}{ Smoking habit } \\
\hline & & $x^{2}$ & $\mathrm{p}$ & $x^{2}$ & $\mathrm{p}$ & $x^{2}$ & $\mathrm{p}$ \\
\hline \multirow[t]{2}{*}{ Pushing } & $\mathrm{A}$ & 107.09 & 0.29 & 15.37 & $0.04 *$ & 4.29 & 0.38 \\
\hline & B & 137.64 & 0.21 & 5.90 & 0.32 & 2.54 & 0.77 \\
\hline \multirow[t]{2}{*}{ Pulling } & A & 119.15 & 0.63 & 6.26 & 0.28 & 2.64 & 0.76 \\
\hline & $\mathrm{B}$ & 128.64 & 0.39 & 5.43 & 0.37 & 3.30 & 0.66 \\
\hline \multirow{2}{*}{ Lifting } & A & 140.78 & 0.16 & 7.75 & 0.17 & 7.77 & 0.17 \\
\hline & B & 106.81 & 0.88 & 9.80 & 0.08 & 1.97 & 0.85 \\
\hline \multirow[t]{2}{*}{ Unloading } & $\mathrm{A}$ & 128.31 & 0.40 & 3.64 & 0.60 & 3.23 & 0.67 \\
\hline & B & 107.81 & 0.86 & 10.30 & 0.07 & 0.92 & 0.97 \\
\hline \multirow[t]{2}{*}{ Rotating loads } & A & 117.73 & 0.67 & 5.38 & 0.37 & 3.79 & 0.58 \\
\hline & $\mathrm{B}$ & 123.25 & 0.53 & 3.80 & 0.58 & 4.99 & 0.42 \\
\hline \multirow[t]{2}{*}{ Holding } & $\mathrm{A}$ & 121.14 & 0.58 & 12.74 & $0.03 *$ & 9.20 & 0.10 \\
\hline & B & 92.75 & 0.98 & 3.73 & 0.59 & 3.58 & 0.61 \\
\hline \multirow[t]{2}{*}{ Rotating while lifting loads } & A & 114.41 & 0.15 & 18.82 & $0.00 *$ & 6.97 & 0.14 \\
\hline & $\mathrm{B}$ & 126.32 & 0.45 & 3.61 & 0.61 & 8.38 & 0.14 \\
\hline \multirow[t]{2}{*}{ Bending } & A & 130.17 & 0.36 & 3.66 & 0.60 & 4.14 & 0.53 \\
\hline & $\mathrm{B}$ & 99.24 & 0.96 & 4.62 & 0.47 & 1.67 & 0.89 \\
\hline \multirow[t]{2}{*}{ Standing statically for $10 \mathrm{~min}$} & A & 165.49 & $0.01 *$ & 14.45 & $0.01 *$ & 3.80 & 0.58 \\
\hline & B & 135.32 & 0.25 & 17.08 & $0.00 *$ & 2.87 & 0.72 \\
\hline \multirow[t]{2}{*}{ Repetitive work } & A & 138.78 & 0.19 & 4.54 & 0.47 & 3.16 & 0.67 \\
\hline & $\mathrm{B}$ & 134.46 & 0.27 & 12.85 & 0.03 & 3.16 & 0.68 \\
\hline \multirow[t]{2}{*}{ Awkward posture } & $\mathrm{A}$ & 99.93 & 0.95 & 3.90 & 0.56 & 3.19 & 0.67 \\
\hline & B & 108.06 & 0.87 & 2.87 & 0.72 & 0.83 & 0.98 \\
\hline \multirow[t]{2}{*}{ Reaching } & $\mathrm{A}$ & 140.04 & 0.17 & 12.42 & $0.03 *$ & 1.26 & 0.94 \\
\hline & B & 124.94 & 0.49 & 24.86 & $0.00 *$ & 6.95 & 0.24 \\
\hline \multirow[t]{2}{*}{ Lifting above head level } & A & 132.21 & 0.31 & 18.23 & $0.00 *$ & 2.77 & 0.74 \\
\hline & $\mathrm{B}$ & 131.09 & 0.34 & 12.08 & $0.03 *$ & 5.27 & 0.38 \\
\hline \multirow[t]{2}{*}{ Working in narrow space } & $\mathrm{A}$ & 102.96 & 0.93 & 5.64 & 0.34 & 1.87 & 0.87 \\
\hline & $\mathrm{B}$ & 111.99 & 0.79 & 5.92 & 0.31 & 2.98 & 0.70 \\
\hline
\end{tabular}

$\mathrm{N}=60: \mathrm{A}=$ Upper back pain: $\mathrm{B}=$ Lower back pain: $\mathrm{x}^{2}=$ Chi squared: $\mathrm{p}^{*}=$ Significant value at level $\leq 0.05$ 
Am. J. Applied Sci., 7 (4): 473-479, 2010

Table 3: Prevalence of back pain

\begin{tabular}{|c|c|c|c|c|c|c|}
\hline Level of pain & Not related & No pain & Uncomfortable & A little pain & A slight pain & Very painful \\
\hline \multicolumn{7}{|c|}{ Body posture pushing } \\
\hline Upper back pain & 43.3 & 25.0 & 11.7 & 10.0 & 10.0 & 0.0 \\
\hline Lower back pain & 43.3 & 10.0 & 5.0 & 15.0 & 15.0 & 11.7 \\
\hline \multicolumn{7}{|l|}{ Pulling } \\
\hline Upper back pain & 36.7 & 23.3 & 15.0 & 10.0 & 13.3 & 1.7 \\
\hline Lower back pain & 36.7 & 13.3 & 11.7 & 13.3 & 16.7 & 8.3 \\
\hline \multicolumn{7}{|l|}{ Lifting } \\
\hline Upper back pain & 1.7 & 35.0 & 18.3 & 20.0 & 23.3 & 1.7 \\
\hline Lower back pain & 1.7 & 11.7 & 6.7 & 21.7 & 38.3 & 20.0 \\
\hline \multicolumn{7}{|l|}{ Unloading } \\
\hline Upper back pain & 33.3 & 23.3 & 6.7 & 15.0 & 18.3 & 3.3 \\
\hline Lower back pain & 33.3 & 18.3 & 15.0 & 6.7 & 16.7 & 10.0 \\
\hline \multicolumn{7}{|l|}{ Rotating } \\
\hline Upper back pain & 45.0 & 20.0 & 10.0 & 15.5 & 8.3 & 1.7 \\
\hline Lower back pain & 45.0 & 13.3 & 5.0 & 15.5 & 16.7 & 20.0 \\
\hline \multicolumn{7}{|l|}{ Holding } \\
\hline Upper back pain & 73.3 & 6.7 & 10.0 & 3.3 & 5.0 & 1.7 \\
\hline Lower back pain & 73.3 & 1.7 & 3.3 & 8.3 & 6.7 & 6.7 \\
\hline \multicolumn{7}{|l|}{ Rotating } \\
\hline Upper back pain & 30.0 & 25.0 & 13.3 & 18.3 & 13.3 & - \\
\hline Lower back pain & 30.0 & 8.3 & 5.0 & 21.7 & 25.0 & 10.0 \\
\hline \multicolumn{7}{|c|}{ Bending while lifting } \\
\hline Upper back pain & 21.7 & 35.0 & 6.7 & 10.0 & 23.3 & 3.3 \\
\hline Lower back pain & 21.7 & 5.0 & 6.7 & 18.3 & 36.7 & 1.7 \\
\hline \multicolumn{7}{|c|}{ Standing statically for $10 \mathrm{~min}$} \\
\hline Upper back pain & 48.3 & 26.7 & 10.0 & 10.0 & 3.3 & 1.7 \\
\hline Lower back pain & 48.3 & 21.7 & 8.3 & 11.7 & 8.3 & 1.7 \\
\hline \multicolumn{7}{|l|}{ Repetitive works } \\
\hline Upper back pain & 41.7 & 20.0 & 8.3 & 10.0 & 13.3 & 6.7 \\
\hline Lower back pain & 41.7 & 15.0 & 5.0 & 16.7 & 13.3 & 8.3 \\
\hline \multicolumn{7}{|l|}{ Awkward posture } \\
\hline Upper back pain & 60.0 & 11.7 & 3.3 & 11.7 & 11.7 & 1.7 \\
\hline Lower back pain & 60.0 & 11.7 & 5.0 & 5.0 & 10.0 & 8.3 \\
\hline \multicolumn{7}{|l|}{ Reaching } \\
\hline Upper back pain & 56.7 & 16.7 & 6.7 & 3.3 & 11.7 & 5.0 \\
\hline Lower back pain & 56.7 & 13.3 & 3.3 & 8.3 & 11.7 & 6.7 \\
\hline \multicolumn{7}{|c|}{ Lifting above head level } \\
\hline Upper back pain & 43.3 & 15.0 & 6.7 & 10.0 & 20.0 & 5.0 \\
\hline Lower back pain & 43.3 & 16.7 & 6.7 & 6.7 & 18.3 & 8.3 \\
\hline \multicolumn{7}{|c|}{ Working in narrow space } \\
\hline Upper back pain & 51.7 & 21.7 & 8.3 & 1.7 & 13.3 & 3.3 \\
\hline Lower back pain & 51.7 & 13.3 & 6.7 & 10.0 & 10.0 & 8.3 \\
\hline
\end{tabular}

Posture analysis during working (WinOWAS): It is just right to continue the study by analyzing further the symptoms and reasons for the back pains among the respondents. WinOWAS was utilized to study the respondents working posture (Kourinka et al., 1987). For the purpose of this study, only one example for each posture will be discussed from each respondent's working area. Table 4 showed that most working postures were in category 3 followed by category 1, 4 and 2 in descending orders.

For back of the body, two active activities were observed occurred the most among the respondents. For certain activities like bending, pushing, pulling and lifting, they were dominated by men respondents whilst rotating and repetitive works were dominated by women respondents. Table 4 showed the analysis on the relationship between working postures and back pain problems. Although there were mechanical aids, a substantial part of transportation of goods requires manual effort. Pushing and pulling activities were done to move baskets of canned foods weighing about 200$600 \mathrm{~kg}$ each in and out mixing areas. While lifting activity includes lifting loads of more than $20 \mathrm{~kg}$ at a time with more than 10 times day ${ }^{-1}$. Lifting above head level only occurred when wrapping plastics need to be refilled into the machines. These activities are categorized in category 3 where contribution to back pain is high. For rotating and repetitive works, the women workers were actually doing those activities during filling up soy sauce bottles; Empty bottles on their left side and the filled up bottles were placed on their right side and the activities were carried out for the whole day. However, these activities are categorized in category 1 where no changes are needed to any part of the study. 
Am. J. Applied Sci., 7 (4): 473-479, 2010

Table 4: Working posture analysis

\begin{tabular}{llc}
\hline Category & Working posture & Percentage \\
\hline 1 & Lifting loads & 30.77 \\
& Rotating while lifting loads & \\
& Standing statically for 10 min or more & \\
& Repetitive work & 7.70 \\
3 & Working in narrow area & 46.20 \\
& Pushing loads & \\
& Pulling loads & \\
& Unloading & \\
& Bending & 15.40 \\
& Reaching & \\
\hline
\end{tabular}

Table 5: Responses regarding exiting ergonomic interventions

\begin{tabular}{lllc}
\hline & Approach & & \\
& - & & \\
Responses & Trainings & PPE & Mechanical \\
\hline Receive & 38.3 & 65.0 & 100 \\
Did not receive & 61.7 & 35.0 & 0 \\
Effective & 82.6 & 84.6 & 100 \\
Not effective & 17.4 & 15.3 & 0 \\
\hline
\end{tabular}

$\mathrm{N}=60$

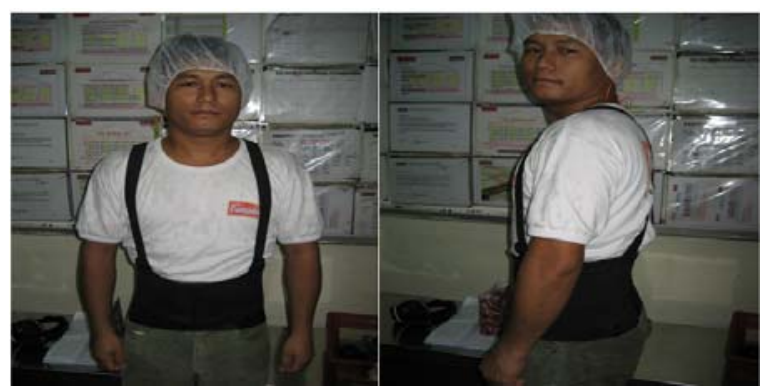

Fig. 1: One worker is shown wearing the back belt

For the hands, most activities were works that were performed lower than shoulder level. However, at certain point of time few workers have to reach and lift loads higher than shoulder level; for example, when the machine needs to be refilled with wrapping plastics. This act fell into category 3 where some improvement needs to be done. From observations, postures that involved the legs were mostly standing for long hours and moving from one place to another place repetitively for the whole shift.

Existing ergonomic interventions: Three parts in the questionnaire identify existing ergonomic interventions practiced in the company. The interventions are categorized in three forms; trainings and education, personal protective equipments and mechanical assistance. From the results, $38.3 \%$ of the respondents received formal trainings from the employer and the rest had never received any form of formal education regarding manual material handlings. However, only $82.6 \%$ reported positive responses regarding the effectiveness of the trainings and the rest believed that the trainings did not help in tackling their back pain problems (Table 5).

The second approach was providing personal protective equipments. $65 \%$ of the respondents received back belt. Only $84.6 \%$ of the back support users responded positively regarding the usage of the belt and the other $15.4 \%$ said that they didn't feel any difference whether they are wearing the belt or not (Fig. 1 and Table 5). However, according to scientific literature study conducted by NIOSH (1996), there is insufficient scientific evidence that back belt actually effective in reducing the risk of back injury. Hence, the institute does not recommend the use of back belts to prevent injuries among workers who have never been injured.

The final approach was providing mechanical material handling devices to move especially heavy loads. Every respondent (100\%) agreed that the assist devices help reduce back pain (Table 5). Among the material handling devices provided are adjustable spring table, hydraulic hand pallet, hand trucks and forklift.

\section{DISCUSSION}

Significant relationships were shown between gender and lower back pain for standing statically for $10 \mathrm{~min}$, reaching posture and lifting loads above head level posture. The study also showed that female workers experienced more back pain as compared to their male co-workers. Significant relationship was also shown between back pain and workers' age. According to Hakkanen et al. (2001), gender differences do not always show significant difference with back problems. However, age always shows significant differences. The same findings were also found by Gilkey et al. (2003).

The result showed some similarity to other study in which LBP was shown to be the highest back pain prevalence (Pinder, 2000; Saraji et al., 2004; Guo et al., 2004). From the findings it is shown that LBP was more problematic than UBP. Hoozemans et al. (2002) and Leclers et al. (2004) showed that there were relationships between pushing loads, pulling loads, lifting loads and both upper and lower back pains.

Study results showed that there were only two significant relationships; between repetitive works and back pain problems and lifting load above head level and back pain problems (both $\mathrm{p}<0.05$ ). Referring to Table 1, it is shown that if one took the leave for back pain problems, the worker actually did not get enough 
rest to heal his back problem. The mean leaves taken per month were shown to be less than 2 days. According to Norris (2000) back pain could be eased only by resting minimally 2 days but not more than 2 weeks consequently as it will cause negative effect.

Although the intervention provided by the employer sounds perfect, back pain still occurs. As shown in Table 5, very few of the respondents were lucky enough to receive trainings regarding good practices in manual material handling. From these few numbers of people, almost half of them said that it was not an effective approach. Perhaps, the trainings and education approach should become a continuous practice; instead of seasonal it should be repeated few times a year. Therefore, reminders about the healthy and proper way of manual material handling could be refreshed occasionally. Whilst many of the respondents thought that the back belt that they received is effective, it is not a recommended approach. It might be a commercial gimmick and yet however it gave good psychological effects to the respondents. Hence, the authors believed that the usage of back belt and its effectiveness should be further studied.

\section{CONCLUSION}

From the study, it was shown that there were no significant relationship between smoking habit and back pain problems. Certain postures like holding loads, standing, repetitive work, reaching and lifting loads above head level showed significant relationship with gender. Female workers gave more complaints that their male companion. Age showed significant relationship only with standing statically posture. The findings also showed that the highest prevalence being lifting activities, $45 \%$ for UBP and $84 \%$ for LBP. The most critical OWAS analysis was for the respondents' back part of the body, where they did a lot of bending, pushing, pulling and lifting and pushing involved loads as heavy as $200-600 \mathrm{~kg}$. The analysis showed that there were significant relationship between repetitive study and lifting above head level (action category 1 and 3) with back pain complaints $(\mathrm{p}<0.05)$. However, although there were back pain complaints, the respondents gave positive responses to the existing interventions provided by the employer.

\section{ACKNOWLEDGMENT}

The researcher would like to acknowledge the financial contributions both from Ministry of Science, Technology and Innovation and Ministry of Higher Education for their grants.

\section{REFERENCES}

Adam, P.S., 2005. Selecting ergonomic tools applied safety and ergonomics. Proceeding of the ASSE Professional Development Conference and Exposition, June 2005, (PDCE'05).

Bernard, B.P., 1997. Musculoskeletal disorders and workplace factors: A critical review of epidemiologic evidence for work-related disorders of the neck, upper extremities and low back. http://www.cdc.gov/niosh/docs/97-141/

Biering-Sorensen, F., C.E. Thomsen and J. Hilden, 1989. Risk indicators for low back trouble. Scand J. Rehabil. Med., 21: 151-157. PMID: 252963

Corner, J.L. and C.W. Kirkwood, 1991. Decision analysis applications in the operations research literature 1970-1989. Operat. Res., 39: 206-219. DOI: $10.1287 /$ opre.39.2.206

Ghaffari, M., A. Alipour, I. Jensen, A.A. Farshad and E. Vingard, 2006. Low back pain among Iranian industrial workers. Occup. Med., 56: 455-460. PMID: 16837536

Gilkey, D.P., T.J. Keefe, P.L. Bigelow, R.E. Herron and K. Duvall et al., 2003. Occupational low back pain in residential carpenters: OWAS categories and force of compression and shear. Proceeding of the 1st Annual Regional National Occupational Research Agenda Young/New Investigators Symposium, June 2003, University of Utah, pp: 35-48.

Guo, H.R., Y.C. Chang, W.Y. Yeh, C.W. Chen and Y.L. Guo, 2004. Prevalence of musculoskeletal disorder among workers in Taiwan: A nationwide study. J. Occup. Health, 46: 26-36. PMID: 14960827

Hakkanen, M., E. Viikari-Juntura and R. Martikainen, 2001. Job experience, work load and risk of musculoskeletal disorders. Occup. Environ. Med., 58: 129-135. DOI: 10.1136/oem.58.2.129

Hoozemans, M.J.M., A.J. Van Der Beek, M. FringsDresen, L.H.V. van der Woulde and F.J.H. van Dijk, 2002. Pushing and pulling in association with low back and shoulder complaints. Occup. Environ. Med. 59: 696-702. DOI: 10.1136/oem.59.10.696

Karhu, O., P. Kansi and L. Kourinka, 1977. Correcting working postures in industry: A practical method for analysis. Applied Ergon., 8: 199-201. DOI: 10.1016/0003-6870(77)90164-8

Koda, S. and H. Ohara, 1999. Preventive effect on low back pain and occupational injuries by providing the participatory occupational safety and health program. J. Occup. Health, 41: 160-165. DOI: 10.1539/joh.41.160 
Kourinka, I., B. Jonsson and A. Kilbom, H. Vinterberg and F. Biering-Sørensen et al., 1987. Standardised Nordic questionnaires analysis of musculoskeletal symptoms. Applied Ergon., 18: 233-237. DOI: 10.1016/0003-6870(87)90010-X

Leclers, A., J.F. Chastang, I. Niedhammer, M.F. Landre and Y. Roquelaure, 2004. Incidence of shoulder pain in repetitive work. Occup. Environ. Med., 61: 39-44. PMID: 14691271

Matilla, M., W. Karwowski and M. Vilkki, 1993. Analysis of working posture in hammering task on building construction sites using the computerized OWAS method. Applied Ergon., 24: 405-412. DOI: 10.1016/0003-6870(93)90172-6

NIOSH, 1996. Back belts, do they prevent injury? DHHS (NIOSH USA) Publication. No. 94-127. http://www.cdc.gov/niosh/backbelt.html

Norris, C.M., 2000. Back Stability. 1st Edn., Human Kinetics, ISBN: 0-7360-0081-X, pp: 272.

Pinder, A.D.J., 2000. Manual handling in the brick production industry: Results of a study of the ergonomics of brick packing. Health and Safety Executive, British Library Document Supply Centre.

http://www.hse.gov.uk/research/hsl_pdf/2000/hs10 0-20.pdf
Punnet, L. and D.H. Wegman, 2004. Work-related musculoskeletal disorders: The epidemiologic evidence and the debate. J. Electromyogr. Kinesiol., 14 : 13-23. $\quad$ DOI: 10.1016/j.jelekin.2003.09.015

Saraji, J.N., M.A. Hassanzadeh, M. Pourmahabadian and S.J. Shahtaheri, 2004. Evaluation of musculoskeletal disorders risk factors among the crew of the Iranian ports and shipping organization's vessels. Acta Med. Iranica, 42: 350-354.

Triano, J.J. and N.C. Selby, 2006. Manual Material Handling To Prevent Back Injury. Spin-Health trsted Information of pain relief. http://www.spinehealth.com/wellness/ergonomics/manual-materialhandling-prevent-back-injury

Yeung, S., A. Genaidy, J. Deddens, C. Shoaf and P.C. Leung, 2003. A participatory approach to the study of lifting demands and musculoskeletal symptoms among Hong Kong workers. Occup. Environ. Med., 60: 730-738. DOI: 10.1136/oem.60.10.730 